\title{
Developing a Simulated-Person Methodology Workshop: An Experiential Education Initiative for Educators and Simulators
}

\author{
Eva Hava Peisachovich ${ }^{1}$, LJ Nelles ${ }^{1,2}$, Samantha Johnson ${ }^{1}$, Laura Nicholson ${ }^{1}$, Raya Gal ${ }^{1}$, Barbara Kerr ${ }^{3}$, Celia \\ Popovic $^{3}$, Iris Epstein ${ }^{4} \&$ Celina Da Silva ${ }^{1}$ \\ ${ }^{1}$ School of Nursing, York University, Toronto, Canada \\ ${ }^{2}$ Mount Sinai Hospital, Toronto, Canada \\ ${ }^{3}$ Teaching Commons, York University, Toronto, Canada \\ ${ }^{4}$ Sally Horsfall Eaton School of Nursing, George Brown College, Toronto, Canada \\ Correspondence: Eva Hava Peisachovich. Address: School of Nursing, York University, Toronto, Ontario, Canada, \\ M3J 1P3, Canada. Tel: 1-416-736-2100 (ext. 33931).
}

Received: December 22, 2016

Accepted: January 19, 2017

Online Published: January 23, 2017

doi:10.5430/ijhe.v6n1p230

URL: http://dx.doi.org/10.5430/ijhe.v6n1p230

\begin{abstract}
Numerous forecasts suggest that professional-competence development depends on human encounters. Interaction between organizations, tasks, and individual providers influence human behaviour, affect organizations' or systems' performance, and are a key component of professional-competence development. Further, insufficient or ineffective communication between professionals is deemed a contributing factor to adverse events worldwide. This underscores the need to provide educators with the tools and education to embed methods in their teaching that will enable learners to effectively intervene in highly charged interpersonal situations and high-risk scenarios; these concerns highlight the value of realistic simulated-experiential approaches, such as the one proposed in this project. The first phase of this project involved conducting a three-day experiential workshop developed at a Canadian university to provide educators with knowledge and skills to work and effectively utilize simulators, enhancing pedagogical classroom practices for teaching undergraduate learners. This workshop's development resulted in numerous benefits. Participation in the workshop provided educators with opportunities for meaningful reflection on their teaching practice and the ability to apply this insight to optimize student learning. It provided theatre students, recruited as simulators as part of this interdisciplinary initiative, to expand their experiences and this will lead to an expanded practicum course for their program. There is now a group of simulators available to educators across the university to include in classroom activities, and lastly there are further iterations of this workshop available for faculty development. This paper reflects on the workshop experiences and the feedback obtained from the participants. Formal and informal feedback obtained provides an understanding of the participants' experiences.
\end{abstract}

Keywords: Simulated-person methodology, Knowledge mobilization, Experiential education, Simulation-based pedagogy, Educational workshop

\section{Introduction}

While much research exists on the impact of simulated-person (SP) methodology on students' skills acquisition, there is little scholarly literature that discusses how best to educate the educators and actor/simulators on how to effectively use this methodology. The aim of this project is to provide educators with the tools needed to apply and embed SP methodology in their teaching and to work with simulators in the context of a teaching-learning setting. In addition, the project proposes a potentially sustainable and affordable model for the training and delivery of SPM. To meet this aim, we conducted a workshop as part of an innovative initiative to embed SP methodology within one Canadian university and gathered data of its efficacy from the participants. We hypothesize that the workshop will aid educators in gaining a deeper understanding of SP methodology, its use and benefits, and how to effectively embed this methodology within their teaching.

There is little research available that discusses this unique aim and involves evaluation of the process of educating or providing educators with the knowledge and skills to embed this pedagogical methodology in their classrooms. The databases CINAHL: Cumulative Index to Nursing and Allied Health (EBSCO) and Nursing and Allied Health Source (ProQuest) were utilized to conduct a search of available literature. The search terms simulation and education were 
used to conduct the initial search and other articles were sourced from the reference list of the populated results. Abstracts were reviewed, and papers that did not relate to simulation in the context of education were removed. The articles selected for this review ranged from the areas of nursing education and medical education to political-science education and other interprofessional sources. While the research indicates that simulation is an effective teaching tool, it can be expensive (Bosse, Nickel, Huwendiek, Schultz, \& Nikendei, 2015) and thus remains underutilized as a pedagogical tool in undergraduate education beyond medicine and nursing.

Given this, it is important to expand on research that explores how to support educators to use SPs effectively and how to embed this methodology in a cost-effective manner. Our proposal to prepare and include theatre students as simulators through the creation of a practicum course in simulation is one such method and the workshop upon which the project is based allowed us to lay the foundation for such an initiative at York University.

\subsection{Relevant Scholarship}

Simulation is a teaching strategy based in experiential learning; it facilitates activities that mimic real-life situations (Jefferies, 2012; Loomis, 2016; McCaughey \& Traynor, 2010; Waxman, 2010). The learner is asked to perform certain skills in the simulation context to engage in learning or determine preparedness for a situation (Harder, 2010). There is a large research focus on clinical-skill acquisition as a learning objective of simulation across the health professions. However, simulation activities can be utilized to develop competence in communication, professionalism, cultural sensitivity, ethics and many other applications, which receive less research emphasis (McGaghie, Issenberg, Petrusa \& Scalese, 2010) particularly in professions outside of health care.

The benefits of simulation include increased confidence in practice, new knowledge generation, and skill acquisition (McCaughey \& Traynor, 2010; McGaghie, Siddall, Mazmanian \& Myers, 2009). This learning strategy supports a safe educational environment in which one can practice and make mistakes without risk to actual persons or in actual environments (Bradley, 2006; McCallum, 2007; Robertson \& Bandali, 2008). The use of simulation-based methodology should involve premeditation of how this learning experience will enhance theory-praxis understanding (Bland, Topping, \& Wood, 2011) and was a starting point for this project. The process of developing simulation scenarios requires thoughtful engagement informed by sound pedagogical frameworks to support robust learning opportunities (Asal \& Blake, 2006; Kelly, Berragan, Husebø \& Orr, 2016). Bland et al. (2011) discuss the importance of evaluating the level of authenticity required in order for the simulation to engage learning and suspend disbelief; this level is informed by the planning process. To ensure these important elements of simulation based education were honoured in our project we chose to locate our pilot in the department of nursing as these faculty were already somewhat familiar with simulation pedagogy and the nature of authentic case-based learning.

While there is a wealth of literature supporting simulation as a validated tool for assessment and learning, many authors agree that there is a lack of empirical evidence related to how scenario development guidelines, and evaluation tools for outcome measurement (Bland et al., 2011; McGaghie et al., 2009; Waxman, 2010) are related to the effectiveness of simulation. Anecdotal evidence and studies that largely evaluate perceptions rather than empirical data contribute to unanswered questions regarding the application of simulation (Harder, 2010; Robertson \& Bandali, 2008). Research regarding the specific scope of this project is scant and testifies to the value that this information will contribute to the body of literature regarding simulation as an educational methodology in undergraduate education. Given that knowledge and skills within the context of simulation-based pedagogy-particularly the use and application of simulated-person methodology - may be limited to educators in health and aviation, this workshop provided further insight into the need for collaborative knowledge and understanding to embed this methodology in the classroom in the university setting more broadly.

\section{Methods}

This pilot workshop was guided by the appreciative-inquiry framework, a strengths-based approach that operates under the basic assumption that "every living system has rich and inspiring accounts of the positive, suggesting that in every organization, group or society something "works"' (Taylor et al., 2012, p. 260). Appreciative inquiry focuses on successes and achievements, guiding participants to magnify and proliferate these positive attributes (Taylor et al., 2012). This framework was developed to initiate and manage personal and organizational change through identification of strengths (Dematteo \& Reeves, 2011). As a group of researchers and educators with a breadth of experience in simulation methodology, we chose appreciative inquiry as a method that would allow us to explore and investigate the strengths of simulation and simulated person methodology as an experiential tool and to dream a design that could be applied in a mutli-disciplinary environment. 
Appreciative inquiry (AI) can be used in multiple ways through research methods that empower participants (Dematteo \& Reeves, 2011). Tosati, Lawthong, and Suwanmonkha (2015) highlight the use of AI in supporting the fundamental learning methods of inquiry, dialogue, reflection, collaboration, and feedback. In nursing practice, there often exist underlying anxieties that can affect group dynamics; these anxieties can be better understood utilizing an AI framework to highlight strengths while confronting damaging group dynamics (Watkins, Dewar, \& Kennedy, 2016). The AI framework supports the creation of a safe environment that promotes personal sharing and the development of deep connections through respect for uniqueness and acknowledgement of diversity (Dematteo \& Reeves, 2011) and aligns appropriately with the exploratory nature of this project to inform teaching and learning through the application of simulated-person methodology. AI was included in the design of the workshop. The workshop had a collaborative model in which simulators and educators were trained in the pedagogy together. Workshop participants included the research team, nursing faculty who would use the developed scenarios in their fall courses, theatre students from the university would act as simulators for the project and members of the Teachings Commons (who were there to learn about simulation so they could best support future roll-out of the project). Imbedding AI in the design of the workshop was intended to:

- enhance participants understanding of their roles in the process

- lead to the development of rich and authentic scenarios as nurse educators provided content and simulators worked with them to make the content play out authentically

- promote the exploration of possible best practices

- promote reflection and feedback on each module of the workshop in order to inform future iterations of the workshop

- develop relationships between educators and simulators and thus creating a safe environment for sharing and deep reflection

- investigate the strengths of human simulation in the translation of theory to practice

- maximize learning for participants and therefore for students

Flip charts, post-it notes and facilitated conversations were used to collect reflective data throughout the workshop process. Follow-up focus groups would further explore the potential for the project moving forward.

A descriptive mixed-method design was employed to gain a better understanding of the participants' experiences of the workshop and their ability to use, apply, and engage with SP methodology within a teaching-learning context. Qualitative data collection was used to determine whether the workshop increased the knowledge and skills of participants (faculty and simulators). Quantitative data collection was used to gain an understanding of whether and how the organization and design of the workshop met the participants' learning needs and facilitated their ability to sustain the knowledge and skills learned.

\subsection{Participants}

The workshop was conducted at York University and included eight participants: four faculty members and four simulators recruited from the university's theatre program. Faculty participants were recruited through purposive sampling from the School of Nursing, as this workshop is part of a pilot project examining the application of the methodology within this context. At the time of the project, the four faculty members taught courses within the undergraduate nursing curriculum. The simulators were recruited through a convenience sample and were paid for their participation. An announcement was emailed to students in the third and forth year of the theatre program.

\subsubsection{Ethical Approval}

The project was approved by the York University Ethics Board. Prior to participating in the workshop, participants received copies of the consent form and associated information and materials about the workshop. On the first day of the workshop, prior to initiation of activities, those who agreed to participate signed the associated consent forms.

\subsection{Workshop Design}

The aim of the workshop was to increase faculty participants' knowledge, skills, and confidence to engage and collaboratively work with simulators and to embed SP methodology in teaching-learning contexts. The workshop was grounded by role-modeling strategies to promote a safe container or environment prompting emotional and physical safety (Rudolph, Raemer, \& Simon, 2014).

A three-day, intensive educational workshop was held in July and August 2016, prior to the term in which this methodology would be applied. Learning methods included introduction to SP methodology for both small and large 
groups. Prior to attending the workshop, participants each received a binder containing reading materials, including copies of journal articles detailing studies used to embed SP methodology and information forms. The binder also provided each participant with a copy of the PowerPoint presentations, a resource list for teaching and learning with simulation, an overview of the advocacy-inquiry method of debriefing, a sample informed consent form, a template for scenario writing, reflection activities, strategies for creating a safe space, and a dictionary of simulation methodology terms and concepts. At the end of each module and throughout the day, participants could record reflections, questions, ideas and feedback. At the end of each day of the workshop, participants completed a questionnaire (see Figure 1). Additionally, at the end of the last day of the workshop, participants completed a survey, as illustrated in Table 2.

\section{Workshop day 1}

What are three things I learned today?

What are two outstanding questions I have after completing the workshop today?

Provide one way I would apply this to my course.

\section{Workshop day 2}

What would I tell a friend about this workshop?

What would I share about this workshop?

What areas were unclear or require further clarification?

What are my thoughts on the collaborative process during this workshop?

\section{Workshop day 3}

What suggestions do I have for future workshops?

What are my thoughts about how the workshop developed over the course of three days?

What are my thoughts about the debrief method that was provided over the course of this workshop? What would I change?

Do I have suggestions on what could be improved in the organization of this workshop? What other topics, tools would I need further training or support with?

Figure 1. Data Collection Questions

Day 1 of the three-day workshop began with an overview of the agenda and discussion of activities planned for each of the days. Participants introduced themselves and shared personal experiences with SP methodology. This was followed by an engaging presentation on the components of simulation-based and experiential learning. During the morning break, participants were encouraged to reflect and provide feedback on the workshop, through a debriefing activity in which participants discussed the thoughts, feelings, and physical sensations they had in response to content and activities; this practice was continued throughout the workshop. The afternoon session saw participants interacting with the concepts of simulation and role play. Considerable time was spent looking at the main differences between simulation and role-play before providing hands-on experience with the scenario-development process. It was stressed to participants that while simulation is a form of role play, simulators are often highly trained in their respective roles, while role play is impromptu and often happens between peers. Simulators are aware of the learning objectives and have been trained to prompt thinking and guide scenarios and to respond to behaviours and affect in specific ways through shifts in their own affect or the delivery of scripted lines.

Day 2 built on the foundational aspects of the previous session and focused on learning the key components of scenario writing. Participants were encouraged to focus on learning outcomes as a guiding factor in the scenario-writing process. They became familiar with the kind of information needed to populate a scenario template both from an educational perspective and from the perspective of the simulators who would play the roles. The use of scripted lines and prompts to guide and redirect scenarios was also discussed. Workshop facilitators were readily available to provide feedback and clarification as needed. The afternoon session was highly interactive; roles were practiced, with educator-participants in the position of the learner experiencing simulation. The facilitators guided this experiential component by highlighting approaches appropriate with different types of learners and discussing the facilitation skills and the level of detail necessary to support SPs in simulation. The day's debriefing provided an opportunity to identify impressions, reflections, and outstanding learning needs.

Day 3 continued in a highly interactive fashion, beginning with reflection on the previous sessions. Themes for the morning encompassed educating the educator to work with and train simulators. These discussions provided 
participants with practical tools to utilize in the simulation experiences that typified the day. Participants had an opportunity to gain experience in various roles in the simulation-based learning experience as they rotated from learner to facilitator, trained SPs in developed scenarios, interacted with a variety of learners, and iteratively fine-tuned written scenarios. In addition to participating in various forms of debriefing, participants completed a qualitative survey at the end of each day (see Figure 1) that provided rich feedback to continuously improve this dynamic workshop. Further, at the end of the last day of the workshop, participants completed a survey (see Table 2).

\subsubsection{Sustainability of the Content and Engagement of Participants in Discussions}

A total of eight hours was spent on large-group activities and thirteen hours on small-group activities. The large-group sessions used didactic and interactive activities that covered content associated with SP methodology. The small-group sessions involved interaction between faculty, facilitators, and simulators. For example, a group of three individuals including one faculty member, one facilitator, and one simulator would work on a scenario, exchanging thoughts and ideas.

Food and beverages were provided for breaks and lunch periods, which helped workshop participants to be focused and present to continue the learning process. The format of the workshop logically and naturally progressed over the three days. Participants were able to discuss aspects of simulation and put theory into practice is a safe, supportive space.

The roles of learner, educator, and simulator were interchanged to provide participants with a deeper understanding of how simulation works from different perspectives. Educators identified specific learner behaviours and were trained to portray these behaviours as a means of field testing the roles to ensure that they would be adjustable to different learners. One facilitator and one SP worked at each station, while faculty members moved around as learners. The objectives of this activity were to a) allow faculty an opportunity to understand what it is like to be a learner, b) provide SPs with experience in how roles can play out differently with different learners, and c) provide faculty and SPs with deeper understanding of the facilitation process.

\subsection{Measures}

Given that the expectation of the workshop was to gain knowledge and skills to understand how to apply SP methodology to meet objectives of a lesson and in the classroom, at the end of each day of the workshop, a questionnaire (see Figure 1) was completed by the participants; these three questionnaires required feedback on the process and learning that occurred during the workshop. Additionally, on the final day of the workshop, participants completed a survey designed to assess the effectiveness of workshop organization and delivery (see Table 2).

\subsection{Data Analysis}

The quantitative data was analyzed using descriptive statistics. The analysis included each participant's total score on the organization and delivery of the workshop. Quantitative and qualitative results were merged during interpretation. Themes identified during quantitative data analysis were compared with qualitative results to explain and describe findings about the workshop and knowledge obtained. The qualitative data gathered over the course of the SP methodology workshop was beneficial in articulating the experience of participants with this pedagogical framework. The feedback received was overwhelmingly positive with $75 \%$ of participants rating the workshop program and medium of groups as excellent. Additionally, $75 \%$ of participants indicated that the workshop was excellent in terms of advancing expertise in SP methodology (See Table 1). In the post-survey, 50\% of participants rated the workshop as good in helping develop confidence to implement SPM in their teaching.

Table 1. Workshop Satisfaction Descriptive Statistic

\begin{tabular}{|c|c|c|c|c|c|}
\hline \multirow{2}{*}{$\begin{array}{l}\text { Rating Categories } \\
\text { How would I rate my knowledge, skills and attitudes } \\
\text { AFTER the workshop? }\end{array}$} & \multicolumn{5}{|c|}{ Percentage of Respondents (\%) } \\
\hline & Poor & Fair & Good & $\begin{array}{l}\text { Very } \\
\text { Good }\end{array}$ & Excellent \\
\hline $\begin{array}{l}\text { 1. I feel confident I can implement SP methodology } \\
\text { in my teaching. }\end{array}$ & & 12.5 & 50 & 25 & 12.5 \\
\hline 2. I feel confident about developing scenarios. & & 12.5 & 37.5 & 37.5 & 12.5 \\
\hline $\begin{array}{l}\text { 3. I feel motivated to apply SP methodology in my } \\
\text { teaching. }\end{array}$ & & & 50 & 25 & 25 \\
\hline
\end{tabular}


Table 2. Effectiveness of Workshop Organization and Delivery

\begin{tabular}{|c|c|c|c|c|c|c|}
\hline \multirow{2}{*}{$\begin{array}{l}\text { Rating Categories } \\
\text { How would I rate the following }\end{array}$} & \multicolumn{6}{|c|}{ Percentage of Respondents (\%) } \\
\hline & Poor & Fair & Good & $\begin{array}{l}\text { Very } \\
\text { Good }\end{array}$ & Excellent & $\begin{array}{l}\text { No } \\
\text { Response }\end{array}$ \\
\hline 1. Workshop program & & & 12.5 & 12.5 & 75 & \\
\hline 2. Material provided & & & 37.5 & 12.5 & 50 & \\
\hline $\begin{array}{l}\text { 3. Balance between presentations, discussions, } \\
\text { and activities }\end{array}$ & & & 12.5 & 37.5 & 50 & \\
\hline 4. Time distribution of the workshop & & & 12.5 & 50 & 25 & \\
\hline 5. Organization of the workshop & & & 25 & 37.5 & 37.5 & \\
\hline $\begin{array}{l}\text { 6. Was group work an effective medium during } \\
\text { the workshop }\end{array}$ & & & & 25 & 75 & \\
\hline $\begin{array}{l}\text { 7. Has the workshop advanced my expertise in } \\
\text { SP methodology application }\end{array}$ & & & 12.5 & 25 & 50 & 12.5 \\
\hline $\begin{array}{l}\text { 8. Has the workshop advanced my expertise in } \\
\text { planning and dealing with SP methodology }\end{array}$ & & & 12.5 & 25 & 50 & 12.5 \\
\hline $\begin{array}{l}\text { 9. Has the workshop increased my knowledge, } \\
\text { skills and attitudes toward SP methodology }\end{array}$ & & & 12.5 & 12.5 & 75 & \\
\hline $\begin{array}{l}\text { 10. Was the feedback received over the course } \\
\text { of the workshop valuable }\end{array}$ & & & & 50 & 50 & \\
\hline $\begin{array}{l}\text { 11. Was the facilitation received for continuing } \\
\text { the work in my course valuable }\end{array}$ & & & 12.5 & 25 & 62.5 & \\
\hline $\begin{array}{l}\text { 12. Has the workshop provided me with the } \\
\text { necessary tools to develop and implement } \\
\text { scenarios for my course }\end{array}$ & & 12.5 & 12.5 & 12.5 & 50 & 12.5 \\
\hline
\end{tabular}

\subsection{Grounding Simulation in Learning Objectives}

Participants expressed increased awareness of the importance of grounding simulation in clear, purposeful learning objectives. One participant noted, "You must be just as clear on what they [students] are needing to learn and this frames how you teach them..." Another commented, "It is imperative to understand that this notion of framing simulation based on learning objectives provides a clearer picture of how learning happens or comes together from the learner's lens." Simulation encounters that are closely developed and aligned with specific learning objectives were viewed as increasing clarity and the effectiveness of the experience.

\subsection{Detailed Scenario Development}

In line with close adherence to learning objectives, participants expressed a heightened awareness of the depth of detail involved in scenario development. The provided template was viewed as a helpful resource to guide scenario development. The opportunity to participate in simulation as learners and facilitators served to both inform scenario development and elicit feedback from various perspectives.

\subsection{Simulation Versus Acting}

Participants described their awareness that simulation requires a different approach from acting in an educational framework. Actors make specific choices in their work that allow their characters to be more "interesting" or "authentic." While simulation requires a lot of the same skills as acting, simulators make shifts in affect behaviour in response to learner behaviour and learning objectives rather than to serve the need of the story or director, as happens with acting. Participants noted that more "interesting" choices associated with acting were not always appropriate to support the learner or the learning objective. 


\subsection{Debriefing}

The structure provided for debriefing differed from traditional feedback and was new for some participants. The response was largely positive to this approach; debriefing, with its focus on observed behaviours rather than on the individual, was viewed as valuable to the simulation experience. The structure was described by participants as "very effective," "clean and simple," and "extremely useful." Participants also noted that a demonstration would have been beneficial to introduce facilitation of the debriefing process prior to engaging in the activity.

\section{Discussion}

The workshop offered insight into experiential-education innovation. Although results of the study indicate that knowledge improves after participation in educational workshops, there is limited evidence regarding a similar improvement in skills. The workshop resulted in an increase in participants' knowledge about the application of SP methodology in the teaching-learning context, particularly the classroom. Given the lack of studies conducted in comparable populations, further research is needed to determine how the application of educational workshops can enhance and sustain teaching skills. Further research is also needed to explore the use of this version of the workshop with faculty teaching other disciplines and among different learner cohorts.

The overall structure of the three-day workshop was viewed as logical, with each day progressively building on the next and providing highly interactive activities through which to connect with faculty and simulators. To improve the quality of the workshop, closer consideration to time management was suggested. Feedback also expressed an interest in maintaining or increasing the level of interactivity and experiential activities. Participants' interest in and enthusiasm for the workshop are apparent in the following qualitative comments:

"It was a great experience with a number of components: a) learning to write roles for simulation gives insight into how much information is required to make it a seamless experience, b) build on giving feedback and building relationships with students/learners."

"The importance and skill of debriefing a given situation ... [ [offers] a deeper understanding of how to elevate situations [and] should help me to more effectively guide my training and learning objectives."

"The interactivity and different activities are useful and great practice for facilitating workshops."

"The simulation scenario template is useful when developing scenarios for my clinical courses."

"Staying committed and authentic is necessary in continuing learning and experience to better ones' education."

The next step in this project will be to embed the SP methodology in the classroom and conduct focus-group interviews with three groups of participants: faculty, simulators and learners.

\subsection{Future Considerations}

As budget and funding constraints pervade the healthcare and education sectors, it is important explore the cost effectiveness of proposed investments. The costs associated with simulation have been historically high, which challenged the acknowledgement of its long-term benefits (Lateef, 2010), but these costs can vary from high to low, "depending on methods, technology, and fidelity of the simulation" (Maloney \& Haines, 2016, p. 2). The foremost goal of simulation as a pedagogy is to enhance learning; however, cost effectiveness is crucial if this educational technique is to be seen as a viable option for institutions (Isaranuwatchai, Brydges, Carnahan, Backstein, \& Dubrowski, 2014).

There is a noticeable gap in the literature regarding cost effectiveness or evaluations of the investment return of simulation education (Isaranuwatchai et al., 2014; Maloney \& Haines, 2016). Individual organizations often attempt to decrease costs of simulation through anecdotal approaches or by brainstorming less expensive means to meet their particular education needs (Chichester, Hall, Wyatt, \& Pomilla, 2014). Maloney and Haines (2016) observe that peers or colleagues can be used as simulators, which can decease costs associated with hiring professional actors. There is a push for simulation education to imbed economic evaluations into the processes surrounding simulation projects (Maloney \& Haines, 2016). One form of economic evaluation is a cost-effectiveness analysis that provides data "to assist decision-makers on how to allocate scarce resources effectively" (Isaranuwatchai et al., 2014, p. 221). These components are scarce in simulation education as "economic evaluations are largely based in a quantitative research paradigm, whereas medical education and educational research is . . predominantly focused on qualitative research methods" (Maloney \& Haines, 2016, p. 4). Thus, there is a large gap in the body of evidence to demonstrate the efficiency of simulated-learning approaches (Maloney \& Haines, 2016). 


\section{Conclusion}

We hypothesize that educating educators to work and teach with SP methodology will provide opportunities for fostering student success, thus creating further opportunities for curriculum synergies. One such opportunity has been to use the experience and learning from this initiative to create a practicum course for theatre students that will serve to provide simulators to educators across the university who have taken the simulation workshop. In support of this, our simulation specialist was invited to pilot possible course material in an applied-theatre course this fall, laying the foundation for providing theatre students with employable post-graduate skills in applied-theatre practice and ensuring an inexpensive and well trained supply of simulators to support the future use of simulation methodology in undergraduate learning. Embedding this methodology reinforces the importance of engaging students through scenarios that simulate the realities and complexities of practice-realities that often do not match the textbook portrayal—and, thus, contribute to their success in their transition to the workplace milieu.

In general, the workshop was successful and laid a foundation for future training programs of this style. Identified problems will allow us to further refine the workshop to meet the needs of educators looking to embed SP methodology in their curricula. The workshop appears to have been highly successful in that it will allow us to design a blueprint for a cross-disciplinary program to provide educators with training in simulation methodology and undergraduate students with an opportunity to practice and develop competencies in their respective fields. Future planning is underway to further develop and refine the work begun with this workshop.

\section{Acknowledgement}

The York University Academic Innovation Fund Grant Category I

\section{Conflict of Interest Disclosure}

The author declares that there are no competing interests.

\section{References}

Asal, V., \& Blake, E. L. (2006). Creating simulations for political science education. Journal of Political Science Education, 2(1), 1-18. https://doi.org/10.1080/15512160500484119

Bland, A. J., Topping, A., \& Wood, B. (2011). A concept analysis of simulation as a learning strategy in the education of undergraduate nursing students. Nurse Education Today, 31, 664-670. https://doi.org/10.1016/j.nedt.2010.10.013

Bosse, H. M., Nickel, M., Huwendiek, S., Schultz, J. H., and Nikendei, C. (2015). Cost-effectiveness of peer role play and standardized patients in undergraduate communication training. BMC Medical Education, 15, 183. https://doi.org/10.1186/s12909-015-0468-1

Bradley, P. (2006). The history of simulation in medical education and possible future directions. Medical Education, 40, 254-262. https://doi.org/10.1111/j.1365-2929.2006.02394.x

Chichester, M., Hall, N. J., Wyatt, T. L., \& Pomilla, R. (2014). A cost - effective approach to simulation - based team training in obstetrics. Nursing for Women's Health, 18, 500-507. https://doi.org/10.1111/1751-486X.12162

Dematteo, D., \& Reeves, S. (2011). A critical examination of the role of appreciative inquiry within an interprofessional education initiative. Journal of Interprofessional Care, 25, 203-208. https://doi.org/10.3109/13561820.2010.504312

Harder, B. N. (2010). Use of simulation in teaching and learning in health sciences: a systematic review. Journal of Nursing Education, 49, 23-28. https://doi.org/10.3928/01484834-20090828-08

Isaranuwatchai, W., Brydges, R., Carnahan, H., Backstein, D., \& Dubrowski, A. (2014). Comparing the cost-effectiveness of simulation modalities: A case study of peripheral intravenous catheterization training. Advances in Health Sciences Education, 19, 219-232. https://doi.org/10.1007/s10459-013-9464-6

Jeffries, P. R. (Ed.). (2012). Simulation in nursing education from conceptualization to evaluation (2nd ed.). New York, NY: National League for Nursing.

Kelly, M. A., Berragan, E., Huseb $\varnothing$, S. E., \& Orr, F. (2016). Simulation in nursing education-international perspectives and contemporary scope of practice. Journal of Nursing Scholarship, 48, 312-321. https://doi.org/10.1111/jnu.12208

Lateef, F. (2010). Simulation-based learning: Just like the real thing. Journal of Emergencies, Trauma, and Shock, 3, 348-352. https://doi.org/10.4103/0974-2700.70743 
Loomis, J. A. (2016). Expanding the use of simulation in nurse practitioner education: A new model for teaching physical assessment. The Journal for Nurse Practitioners, 12(4), 151-157. https://doi.org/10.1016/j.nurpra.2015.11.010

Maloney, S., \& Haines, T. (2016). Issues of cost-benefit and cost-effectiveness for simulation in health professions education. Advances in Simulation, 1:13. https://doi.org/10.1186/s41077-016-0020-3

McCallum, J. (2007). The debate in favour of using simulation education in pre-registration adult nursing. Nurse Education Today, 27, 825-831. https://doi.org/10.1016/j.nedt.2006.10.014

McCaughey, C., \& Traynor, M. (2010). The role of simulation in nurse education. Nurse Education Today, 30, 827-832. https://doi.org/10.1016/j.nedt.2010.03.005

McGaghie, W., Issenberg, S., Petrusa, E., \& Scalese, R. (2010). A critical review of simulation-based medical education research: 2003-2009. Medical Education, 44, 50-63. https://doi.org/10.1111/j.1365-2923.2009.03547.x

McGaghie, W., Siddall, V., Mazmanian, P., \& Myers, J. (2009). Lessons for continuing medical education from simulation research in undergraduate and graduate medical education: Effectiveness of continuing medical education: American College of Chest Physicians Evidence-Based Educational Guidelines. Chest, 62S-68S. https://doi.org/10.1378/chest.08-2521

Robertson, J. \& Bandali, K. (2008). Bridging the gap: Enhancing interprofessional education using simulation. Journal of Interprofessional Care, 22, 499-508. https://doi.org/10.1080/13561820802303656

Rudolph, L. W., Raemer, D. B., \& Simon, R. (2014). Establishing a safe container for learning in simulation: The role of the presimulation briefing. Simul Healthc. 9, 339-349. https://doi.org/10.1097/SIH.0000000000000047

Taylor, C., Mills, A., Schmied, V., Dahlen, H., Shuiringa, W., \& Hudson, M. E. (2012). What works to engage young parents into services? Findings from an appreciative inquiry workshop. Contemporary Nurse: A Journal For The Australian Nursing Profession, 42, 258-271. https://doi.org/10.5172/conu.2012.42.2.258

Tosati, S., Lawthong, N., \& Suwanmonkha, S. (2015). Development of an appreciative inquiry and assessment processes for students' self-knowing and self-development. Procedia-Social and Behavioral Sciences, 191, 753-758. https://doi.org/10.1016/j.sbspro.2015.04.422

Watkins, S., Dewar, B., \& Kennedy, C. (2016). Appreciative inquiry as an intervention to change nursing practice in in-patient settings: An integrative review. International Journal Of Nursing Studies, 60, 179-190. https://doi.org/10.1016/j.ijnurstu.2016.04.017

Waxman, K. (2010). The development of evidence-based clinical simulation scenarios: guidelines for nurse educators. Journal Of Nursing Education, 49, 29-35. https://doi.org/10.3928/01484834-20090916-07 